\title{
Deletion 7q Abnormality in a Childhood Pre B All: A Case Report and Review of Literature
}

\author{
Zainab Sharif ${ }^{1 *}$, Munira Borhany ${ }^{2}$, Tahir Sultan Shamsi² \\ ${ }^{1}$ Department of Pediatric Hematology, National Institute of Blood Disease and Bone Marrow Transplantation, Karachi, Pakistan. \\ ${ }^{2}$ Department of Clinical Hematology, National Institute of Blood Disease and Bone Marrow Transplantation, Karachi, Pakistan.
}

\begin{abstract}
Aim: In childhood and adult acute myeloid leukemia and myelodysplastic syndrome chromosome 7 aberrations are not an uncommon finding. But in childhood acute lymphoblastic leukemia it is rarely seen. In this case we identified a rare cytogenetic aberration in a girl with Precursor B cell acute lymphoblastic leukemia.
\end{abstract}

Method: Ten and a half year old girl presented with complaints of fever for two weeks and generalized body swelling for ten days. She was anemic, tachycardia with mild hepatosplenomegaly. She had raised TLC-67x10 $/ \mathrm{L}$ with 52\% blasts. MLL gene and BCR-ABL were negative.

Result: Our patient cytogenetic analysis showed deletion 7q22-34.

Conclusion: Studies have shown that the long arm of 7q from 7q22-q36 has many important tumor suppressor genes located on it. Thus its deletion results in increased Leukemogenesis propensity. It will be interesting to find any interconnection between myeloid and lymphoid clones and chromosome 7 abnormalities.

Keywords: Pre B ALL, Chromosome 7, Deletion 7q22-34, Tumor suppressor gene, Leukemogenesis, Cytogenetics.

\section{INTRODUCTION}

Childhood Acute Myeloid Leukemia and Preleukemic Myelodysplastic Syndrome are linked to cytogenetic abnormalities involving chromosome 7 , like deletions of $7 \mathrm{q}$ and $7 \mathrm{p}$ or monosomy 7 [1]. All of these aberrations are linked with guarded prognosis [2-5]. In children, it is often associated with juvenile chronic myeloid leukemia [6]. Constitutional childhood disorders like NF1, Fanconi's anemia and Down syndrome also has a propensity to develop leukemia that has a distinct entity called Monosomy 7 syndrome. The 7q deletion in myeloid disorders shows that the RAS protein-signaling pathway is involved. There are two commonly deleted regions (CDR) one at $7 \mathrm{q} 22$ and the other at 7 q31-34 [7-9].

\section{CASE PRESENTATION}

A girl aged ten and a half years presented with history of fever for two weeks and generalized body swelling for ten days. On examination, she was sick looking and anemic. Her vitals were temperature $98 \mathrm{~F}$, heartbeat was $100 / \mathrm{min}$, and respiratory rate was $16 / \mathrm{min}$, blood pressure $90 / 60 \mathrm{mmHg}$ and oxygen saturation $98 \%$ in room air. She had bilateral cervical lymphadenopathy. Her abdominal examination revealed a liver 2 fingers palpable below right costal margin and spleen tip palpable. Rest of the systemic examination was unremarkable. Her CBC showed Hb-11.6 g/dl, MCV-87fl, MCH-28pg, MCHC-32 g/dl, TLC-67x10 $/ \mathrm{L}$,

*Address correspondence to this author at the Department of Pediatric Hematology, National Institute of Blood Disease and Bone Marrow

Transplantation, Karachi, Pakistan E-mail: drzainabsharif@yahoo.com
Platelet-267x $10 \% / \mathrm{L}$, and Blasts- 52\%.Blood, urine and throat cultures were negative. Her ultrasound abdomen showed mild hepatosplenomegaly. Bone marrow and findings of immunophenotyping (CD19 +, CD 20 +, CD79a +, CD 3 -, Tdt +, MPO -) were consistent with Pre B ALL (Fig. 1). Cytogenetic analysis showed 46XX deletion $7 \mathrm{q}$ in all the 15 metaphases examined (Fig. 2). Molecular cytogenetics by FISH did not identify MLL while BCR-ABL translocation (p-190) by PCR was found to be negative. There was no involvement of central nervous system with leukemia as CSF examination was clear. Initially, she presented with high TLC count that decreased after one week of starting dexamethasone. She was given poor risk UK ALL-XI chemotherapy protocol. Her post-induction bone marrow was in remission and day 29 minimal residual disease study (MRD) was negative. Early intensification therapy was given and currently she is on Interim maintenance.

\section{IMMUNOPHENOTYPING RESULTS}

The immunophenotyping analysis showed $74 \%$ medium sized blasts (forward light scatter properties). These blasts show following Immunophenotypes findings: CD45(+), CD19(+), CD79a(Dim +$), \quad \mathrm{TdT}+, \mathrm{CD} 13(+), \mathrm{CD} 33(+), \mathrm{CD} 117(+)$, CD34(+), CD5(-), CD10(-), CD20(-), CD64(-), CD4(-), CD7(-), Intracytoplasmic MPO (-), \& cCD3(-). In addition, it shows $0.72 \%$ benign B-lymphocytes, $5.2 \%$ benign T-lymphocytes, and $13.0 \%$ granulocytes. Rest of the events was comprised of debris. 


\section{Interpretation}

Morphologic and immunophenotyping features are in favor of "Precursor B-cell Acute Lymphoblastic Leukemia.

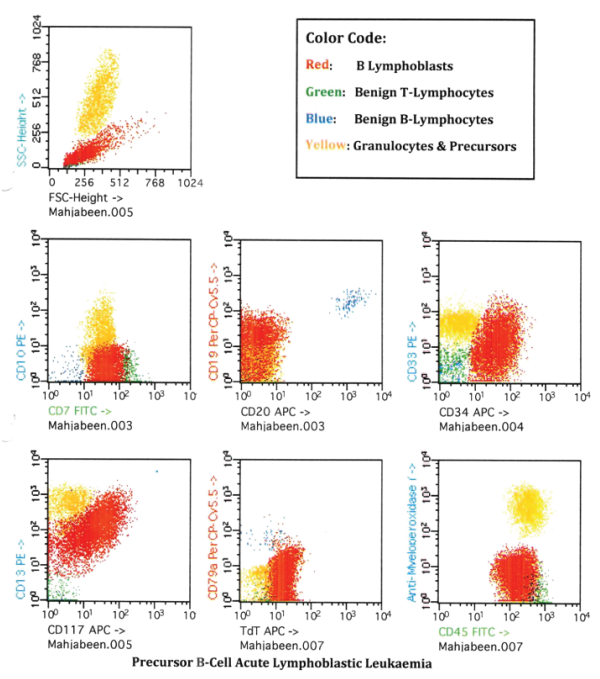

Fig. (1). Scatterplots of Flow cytometric Analysis Revealed Precursor-B cell ALL.

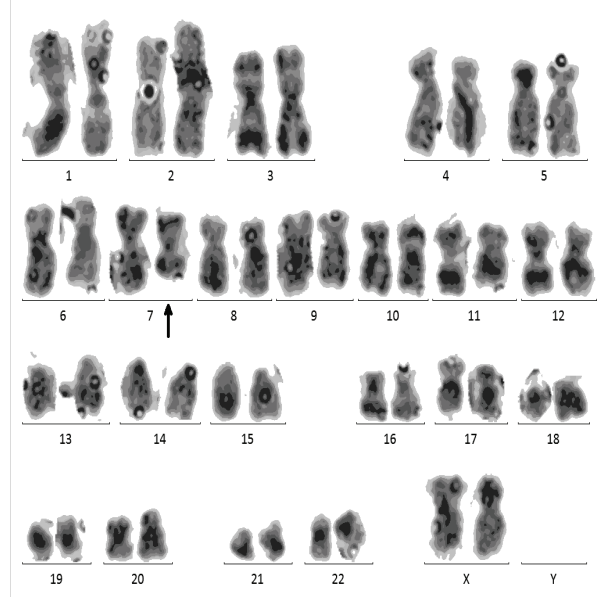

Fig. (2). 46 XX, del (7) (q22q34)[15] 15 Metaphases were Counted All Cells (100\%) Showed 46 Numbers of Chromosome with del (7q).

\section{Conclusion}

Our patient is diagnosed with pre B ALL with cytogenetic abnormality of deletion $7 q 22-34$, that is a very rare entity in childhood ALL.

\section{DISCUSSION}

Deletion of chromosome 7 is extremely rare in acute lymphoblastic leukemia in children. Deletion $7 \mathrm{p}$ has a poor prognosis in childhood ALL. As far as deletion $7 q$ is concerned, poor outcome is not reported in this condition. Monosomy 7 also has a relatively poor event free survival in children with ALL. Previously, it has been hypothesized that chromosome $7 \mathrm{q}$ contains a culprit tumor suppressor gene, which predisposes to leukemia but it has not been proved yet. Other studies also support the fact that chromosome 7 at bands $7 q 22$ and 7q34q36 also contains the genes responsible for Leukemogenesis. With the availability of FISH (fluorescence in situ hybridization) studies, the region $7 q 22$ has been studied in detail and other genes have also been identified. Involvement of other genes on chromosome 7 is also strongly suspected. Further studies are needed to explore their association with different types of leukemia and their prognosis. The DNA structure and sequence of chromosome 7 is particularly very fragile and this is the reason why it leads to a total or partial chromosomal 7 losses. Philadelphia chromosome in adults with ALL is a poor prognostic factor and when this is associated with chromosome $7 \mathrm{q}$ deletion and monosomy 7 , then this further has an additive effect on its outcome.

Childhood ALL having deletion 7p and monosomy 7 is a distinct entity from those having same aberrations in myeloid leukemia. It has been hypothesized that a tumor suppressor gene has been identified on chromosome $7 q$ that is responsible for the predisposition of leukemia. There are two areas on chromosome $7 \mathrm{q}$ at bands $7 \mathrm{q} 22$ and $7 \mathrm{q} 34-36$ with genes responsible for Leukemogenesis. The significance of these regions has been confirmed by molecular analysis. $7 \mathrm{q} 22$ region has been clearly defined by FISH analysis and certain genes have been identified for further analysis. With ongoing research there is a possibility of more than one gene located on chromosome 7 that is involved in Leukemogenesis. With prompt identification of these genes it will be possible to find clear association between the phenotype and prognosis. As chromosome 7 is predisposed to partial or complete losses, it maybe speculated that the chromosomal DNA is very fragile. Adults with Philadelphia positive ALL has also been reported with monosomy 7 and deletion 7 [10].

Human chromosome 7 has been extensively studied and the band analysis of the long arm of chromosome 7 has shown the presence of two critical regions one in band $7 q 22$ and a second in band 7q32q35 $[9,11,12]$. The molecular analysis of proximal critical region in $7 \mathrm{q} 22$ is very intriguing and FISH and $\mathrm{LOH}$ studies have revealed important regions in bands 7q22-q31 that have shown deletion, translocation or inversion breakpoints in myeloid disorders [13-15]. All these events of recurrent loss of genetic material suggest that absence of the functioning tumor suppressor gene leads to Leukemogenesis.

In a series of 15 patients with myeloid or lymphoid malignancies, Le Beau et al. described $3 \mathrm{MB}$ deleted region in band $7 q 22$ [16]. A study conducted by Rodrigues et al. in 54 patients with MDS and AML, bands 7q22 and 7q32 were the two most commonly deleted regions in proximal and distal regions respectively [17]. 
In our patient, cytogenetics revealed deletion 7q22-q34 but the novelty of this case was that she was diagnosed as acute pre B-lymphoblastic leukemia, while the literature reveals that this type of deletion is a characteristic feature of AML and MDS both in pediatric and adults. However, it is interesting to know that chromosome 7 deletions are also associated with acute lymphoblastic leukemia as it is present in our case and only a few other cases as well. It will be a great area of research to find out any relation between the myeloid and lymphoid clones and chromosome 7 aberrations and its clinical implications. Also, the role of tumor suppressor genes involved in chromosome 7 deletions in interconnecting these two distinct types of leukemia. Follow-up of this patient during and after treatment will reveal about her outcome.

\section{CONFLICT OF INTEREST}

Declared none.

\section{ACKNOWLEDGEMENTS}

Declared none.

\section{REFERENCES}

[1] Luna-Fineman S, Shannon KM, Lange BJ. Childhood monosomy 7: Epidemiology, biology, and mechanistic implications. Blood 1995; 85(8): 1985-99.

[2] Grimwade D, Walker H, Oliver F, et al. The importance of diagnostic cytogenetics on outcome in AML: Analysis of 1,612 patients entered into the MRC AML 10 trial. Blood 1998; 92(7): 2322-33.

[3] Mauritzson N, Johansson B, Albin M, et al. Survival time in a population-based consecutive series of adult acute myeloid leukemia-the prognostic impact of karyotype during the time period 1976-1993. Leukemia 2000; 14(6): 1039. DOI: 10.1038/sj.leu. 2401788

[4] Mrózek K, Heinonen K, Bloomfield CD. Prognostic value of cytogenetic findings in adults with acute myeloid leukemia. Int J Hematol 2000; 72(3): 261-71.

[5] Slovak ML, Kopecky KJ, Cassileth PA, et al. Karyotypic analysis predicts outcome of preremission and postremission therapy in adult acute myeloid leukemia: A Southwest Oncology Group/Eastern Cooperative Oncology Group Study. Blood 2000; 96(13): 4075-83.

[6] Emerling BM, Bonifas J, Kratz CP, et al. MLL5, a homolog of Drosophila trithorax located within a segment of chromosome band 7q22 implicated in myeloid leukemia. Oncogene 2002; 21(31): 4849. DOI: 10.1038/sj.onc.1205615

[7] Fischer K, Fröhling S, Scherer SW, et al. Molecular cytoge- netic delineation of deletions and translocations involving chromosome band 7q22 in myeloid leukemias. Blood 1997; 89(6): 2036-41.

[8] Koike M, Tasaka T, Spira S, Tsuruoka N, Koeffler HP. Allelotyping of acute myelogenous leukemia: loss of heterozygosity at 7q31. 1 (D7S486) and q33-34 (D7S498, D7S505). Leuk Res 1999; 23(3): 307-10. DOI: 10.1016/S0145-2126(98)00159-3

[9] Le Beau MM, Albain K, Larson R, et al. Clinical and cytogenetic correlations in 63 patients with therapy-related myelodysplastic syndromes and acute nonlymphocytic leukemia: Further evidence for characteristic abnormalities of chromosomes no. 5 and 7. J Clin Oncol 1986; 4(3): 325-45. DOI: 10.1200/JCO.1986.4.3.325

[10] Dabaja B, Faderl S, Thomas D, et al. Deletions and losses in chromosomes 5 or 7 in adult acute lymphocytic leukemia: Incidence, associations and implications. Leukemia 1999; 13(6): 869. DOI: 10.1038/sj.leu.2401430

[11] Johansson B, Mertens F, Mitelman F. Cytogenetic deletion maps of hematologic neoplasms: Circumstantial evidence for tumor suppressor loci. Genes Chromosomes Cancer 1993; 8(4): 205-18. DOI: $10.1002 /$ gcc.2870080402

[12] Neuman W, Rubin C, Rios R, et al. Chromosomal loss and deletion are the most common mechanisms for loss of heterozygosity from chromosomes 5 and 7 in malignant myeloid disorders. Blood 1992; 79(6): 1501-10.

[13] Kiuru-Kuhlefelt S, Kristo P, Ruutu T, Knuutila S, Kere J. Evidence for two molecular steps in the pathogenesis of myeloid disorders associated with deletion of chromosome 7 long arm. Leukemia 1997; 11(12): 2097. DOI: 10.1038/sj.leu.2400881

[14] Lewis S, Abrahamson G, Boultwood J, Fidler C, Potter A, Wainscoat JS. Molecular characterization of the $7 \mathrm{q}$ deletion in myeloid disorders. Br J Haematol 1996; 93(1): 75-80. DOI: 10.1046/j.1365-2141.1996.4841025.x

[15] Liang H, Fairman J, Claxton DF, Nowell PC, Green ED, Nagarajan L. Molecular anatomy of chromosome 7q deletions in myeloid neoplasms: evidence for multiple critical loci. Proc Natl Acad Sci 1998; 95(7): 3781-5. DOI: 10.1073/pnas.95.7.3781

[16] Beau M, Davis E, Eisenbart J, Larson R, Green E. Cytogenetic and molecular delineation of a region of chromosome 7 commonly deleted in malignant myeloid diseases. Blood 1996; 88(6): 1930-5.

[17] Velloso ERP, Michaux L, Ferrant A, et al. Deletions of the long arm of chromosome 7 in myeloid disorders: loss of band 7q32 implies worst prognosis. Br J Haematol 1996; 92(3): 574-81. DOI: 10.1046/j.1365-2141.1996.d01-2683.x 